\title{
NORMATIVIDAD FISIOLÓGICA Y NOCIVIDAD AMBIENTAL: ASPECTOS BIOÉTICOS DE LAS METÁFORAS CIENTÍFICAS
}

\section{Fernando Lolas Stepke*}

\begin{abstract}
Resumen : Este artículo examina históricamente la influencia social de la fisiología científica como fundamento de la medicina y la tensión entre lo universal y cosmopolita de la ciencia y lo particular del contexto cotidiano. Esta tensión se vincula a la metáfora de la máquina, central en la fisiología del siglo XIX, modificada por las ciencias sociales y humanas, que introducen la historicidad (no la simple temporalidad) como factor diferenciador. La normatividad fisiológica encuentra límites de aplicación en la medicina social, en la elaboración de pautas de rendimiento laboral y deportivo y en la consideración de las nocividades ambientales. Se sugiere que la construcción discursiva de las metáforas no explícitas permite establecer el diálogo entre racionalidades y personas y de este modo facilita la deliberación bioética.
\end{abstract}

Palabras clave: Fisiología, corporalidad, historicidad, ambiente

\section{PHYSIOLOGICAL REGULATION AND ENVIRONMENTAL HARMFULNESS: BIOETHICAL ASPECTS OF SCIENTIFIC METAPHORES}

Abstract : This article examines historically the social influence of scientific physiology as the foundation of medicine and the tension between cosmopolitan and universal science and particular daily contexts. These tension is traced back to the machine metaphor, central in nineteenth century physiology, modified by the human and social sciences, which introduce "historicity" (as different from mere temporality) as a modifying factor. Physiological regulations find limits of application in social medicine, in the development of standards in work and sports and in the assessment of environmental harmfulness. Discursive construction of implicit metaphors is proposed as a means for establishing a dialogue between rationalities and persons, thus permitting bioethical deliberation.

Keywords: physiology, embodiment, historicity, environment.

\section{NORMATIVIDADE FISIOLÓGICA E PREJUÍZO AMBIENTAL: ASPECTOS BIOÉTICOS DAS METÁFORAS} CIENTÍFICA

Resumo: Este artigo examina, através de perspectiva da história, a influência social da fisiologia científica como fundamento da medicina, assim como a tensão entre o universal e o cosmopolita, o particular no contexto cotidiano da ciência. Esta tensão está vinculada com a metáfora da máquina que é central na fisiologia do séc. XIX e modificada pelas ciências sociais e humanas que introduziram a historicidade (não a simples temporalidade) como fator diferenciador. A normatividade da fisiologia apresenta limites de aplicação na medicina social, na elaboração de pautas de rendimento laborativo e esportivo, bem como na consideração de prejuízos ambientais. Sugere-se que a construção discursiva das metáforas não explícitas permita estabelecer o diálogo entre racionalidades e pessoas e, deste modo, facilitar a deliberação bioética.

Palavras chaves: Fisiologia, corporalidade, historicidade, ambiente

* Profesor Titular de la Facultad de Medicina de la Universidad de Chile. Director del Programa Regional de Bioética OPS/OMS.

Correspondencia: lolasf@chi.ops-oms.org 


\section{Historicidad y realidad corporal}

toria.

Una persona es un individuo con his-

Esta afirmación encuentra su fundamento en las aportaciones de las ciencias humanas, que rescataron para la mirada científica la historicidad (temporalidad vivida o experimentada) y por ende la fluidez de la realidad. El psicoanálisis agregó a la historicidad general la historia propia y peculiar de cada sujeto. Somos nuestro pasado, en tanto pasado hecho de experiencias individuales y no simple acontecer. El tiempo cronológico del cosmos no es igual al tiempo significativo de la vida.

En la medicina científiconatural esta forma de temporalidad perturba la concepción del cuerpo en tanto máquina inmutable de caracteres universales. El momento germinal de la fisiología científica, durante el siglo XIX, define esta ciencia como la que se ocupa de "las partes de los organismos", describe con exactitud su funcionamiento y determina canónicamente la normalidad. En otro lugar hemos observado la constricción a que se somete la voz "fisiología" en el curso de su historia: de concepción global de la naturaleza, pensada en sus permanencias y en sus cambios, pasa a significar naturaleza del hombre (ejemplarmente en la obra de Jean Fernel, en el siglo XVI), luego, doctrina de las funciones de las partes de los organismos (paradigmáticamente en la obra de Johannes Müller y Carl Ludwig, durante el siglo XIX) y finalmente investigación de sus constituyentes elementales y las formas de su vinculación (1). Hoy día, la polémica sobre los conceptos empleados en la ciencia fisiológica, aunque no renueva la contienda entre mecanicismo y vitalismo como formas de explicación, pasa por la naturaleza discursiva de las ciencias, la construcción societaria de sus conceptos y la importancia de sus metáforas (2). Una "historia del cuerpo" tal y como fue propugnada por los historiadores de las mentalidades y por los estudios sociales de las ciencias, no consiste solamente en una "cartografía" de sus representaciones. Esencialmente, se trata de indagar en qué forma estas representaciones determinaron y determinan el comportamiento de las personas en sociedad. En el imaginario colectivo, el imperio de estas representaciones sobrepasa ampliamente los contornos y los límites de los grupos profesionales (3). A menudo, los mismos especialistas sufren inadvertidamente la influencia de concepciones forjadas por el pensamiento profano y las inercias de sus creencias y cultura. La tarea de "desenmascarar lo real", poner de manifiesto aquellas inercias intelectuales que ni sus mismos poseedores creen poseer, es una definitiva contribución al establecimiento del diálogo y por ende a una clarificación de los supuestos morales que impregnan la acción socialmente relevante.

Probablemente no es novedoso reconocer que en la medicina, tomada aquí como campo privilegiado para el examen de tal acción, entran en permanente conflicto una visión universal y cosmopolita, de "leyes naturales" válidas en todo tiempo y lugar, con concepciones particulares y locales, codificadas en aforismos prácticos y basadas en la prudencia personal, vigentes en la comunidad específica. Esta vieja tensión entre "teoría" y "práctica", tan vieja que ya está en el Canon de Ibn Sina (Avicena), del siglo X, se resuelve a menudo en la hegemonía del punto de vista "científico" en las sociedades llamadas desarrolladas e influencia sus convicciones y formas de vida. Esta identificación entre pensar científico, leyes universales y desarrollo económicocultural puede llevar a otras sociedades a adoptar connotaciones y resonancias, especialmente simbólicas y afectivas. Como este proceso de asimilación puede ocurrir acrítica o inadvertidamente puede conducir a una obsecuente aceptación (una suerte de paternalismo cultural) o a antagonismos contra el "imperialismo" de lo foráneo y lo "global".

"Piense universalmente, actúe localmente”, lema de la Organización Mundial de la Salud, recoge esta tensión y la convierte en directriz positiva para la promoción y protección de la salud. Entre el "cuerpo universal" (la "ciencia cosmopolita") y la "historia local" (el "mundo de la vida") se establece una dinámica de considerable importancia para la reflexión sobre normas y comportamientos. Aunque la fisiología del siglo XIX incorporó la temporalidad al discurso científico, las aportaciones de las ciencias sociales y humanas la enriquecieron con la historicidad, la temporalidad vivida y experimentada por los sujetos. Esta es 
la influencia moduladora que vincula al cuerpo con la cultura y posibilita así la reflexión moral.

\section{Las metáforas de la ciencia}

La potencia de las metáforas procedentes de las ciencias no depende sólo de la plasticidad con que pueden ser transferidas a otras disciplinas o de la justeza de su aplicación a ciertas situaciones colectivas. Hay en ellas una dosis de "sobresignificación" que hace imperativo su estudio en el contexto de las culturas, toda vez que así se ponen de manifiesto ecos reprimidos, tradiciones no vigentes pero poderosas y significados o significantes de fuerte influjo social aunque ignorados. Sólo como ejemplo, la idea de que la medicina como práctica social se institucionaliza de formas diversas y con diferente contextura ética da lugar a intentos de diseño y reforma de sistemas de cuidado de la salud que sólo superficialmente son distintos. Asistimos en este terreno a distinciones sin diferencia y al embelesamiento por los medios técnicos ignorando la importancia de los fines sociales. En términos de la aceptabilidad de algunas reformas y del grado de satisfacción de los "usuarios", éstos pueden ser más importantes que aquellos.

Interesa especialmente destacar que la noción de "extraños morales"(4) que tan útil papel juega en las discusiones bioéticas debe complementarse con la de "extraños epistémicos", toda vez que las personas, aunque usen las mismas palabras, no "saben" lo mismo ni se representan nada semejante a su conjuro. Por ejemplo, para entender el significado del término hipotálamo es preciso, aparte su definición de diccionario, entrar en una socialización específica en que este término se construye, desconstruye y reconstruye a tenor de avances instrumentales en las formas de su investigación y representación. De igual modo ocurre con conceptos aparentemente menos concretos e incluso con la descripción de procesos. Un gran desafío para una disciplina dialógica (y la bioética es tal por excelencia) es la construcción de "puentes" y mediaciones que permitan el reconocimiento recíproco de los interlocutores y por ende la construcción de una praxis común, con significado social amplio (esto es, acciones que sean inteligibles y relevantes para expertos y profanos y conciten adhesión generalizada) (5). Es en tal sentido que se impone una sucinta aproximación a las nociones de organismo "normal" y ambiente "adecuado" a tal normalidad. Para realizarla, han de considerarse fundantes las metáforas de las ciencias fisiológicas, por su reconocida influencia y su hegemónica supremacía en las concepciones de lo humano "sano". Explorando estas metáforas, sus orígenes y significaciones, sus transformaciones y aplicaciones, sus variantes y migraciones, es posible aproximarse a aquel substrato de creencias compartidas que justifican y legitiman el diálogo interpersonal. No está demás recordar que la noción de Lebenswelt, mundo vital, interpela precisa-mente este estrato de creencias, expectativas, acciones, que constituyen el ethos de un grupo humano, antes de cualquier determinación debida a educación, género o recursos.

\section{La fisiología humana: de la descripción a la norma}

Durante el siglo XIX, pero especialmente en el XX, se impuso la idea de que el progreso, además de deseable, podía ser patógeno. La patogenicidad radicaba, por ejemplo, en las demandas excesivas que imponía a la capacidad de adaptación del organismo humano. La industrialización fue denunciada como un factor que extenuaba a las personas obligándolas a un trabajo monótono, carente de sentido, alienante. Aparte de su expresión en la teorización social y en la temprana denuncia del capitalismo como causante de males colectivos, el pensamiento médico acuñó expresiones que tendían a traducir su potencial patogénico. Así, la neurastenia era la consecuencia de ese género de vida impuesto por la civilización, ajeno a las demandas y necesidades de la existencia saludable que podía encontrarse en la rusticidad del campo o remotas épocas de bienestar humano. Las utopías que florecieron en los siglos XIX y XX cambiaron de signo muchas veces. En ocasiones, el lugar óptimo (eu-topía) se imaginaba en un pasado lejano (el "buen salvaje" habría sido benévolo y manso) o bien en un venturoso futuro (habría bienestar y concordia en la "sociedad sin cla- 
ses"). El factor de la técnica aparece con apariencia "jánica", de doble faz: es bueno en algunos aspectos, malo en otros. Toda la teorización decimonónica que en definitiva establece el ámbito de las ciencias humanas y sociales como campo especial se inicia con la denuncia de algún factor patógeno en el progreso: la alienación, el nihilismo, la adaptación a condiciones anómalas ponen a prueba este "hombre" que la ciencia concibe, lo irritan, deterioran y exigen más allá de sus posibilidades de adaptación. Con ello, lo sacan de lo que es normal y lo "desvían", ya sea en sentido orgánico o en sentido espiritual.

Sin embargo, no menos artificioso que la denuncia es aquello que se denuncia. La imagen del ser humano que fragua la fisiología del novecientos es tan artificial como la sociedad que enfrenta. Se repelen y atraen mutuamente visiones y concepciones. Los fisiólogos descubren en la estabilidad relativa de las funciones orgánicas la clave de la libre existencia de los organismos. "La constancia del medio interno, escribirá Claude Bernard, es condición de la existencia libre". Esta fijeza del milieu interieur devendrá en el concepto técnico de homeostasis como clave para entender el metabolismo y los procesos adaptativos. De allí derivará la poderosa tradición de la investigación sobre el "estrés" y la noción de una "patogenicidad universal" del ambiente, concebido como inagotable fuente de agresiones y demandas (microorganismos causantes de enfermedades, noxas ambientales debidas a la temperatura o las radiaciones, relaciones interpersonales patogénicas, substancias químicas dañinas) (6).

En vano se buscaría en la fisiología académica la clave interpretativa de la imagen de ser humano que se forja a su amparo. La ciencia describe, enuncia principios generales, leyes de la naturaleza que se cumplen ineluctablemente y son válidas para todos los seres humanos o, más generalmente aún, para todos los mamíferos o todos los seres vivos.

Pero no da razón de sus enunciados, porque la ciencia del positivismo se atiene a hechos (facts), no considera percepciones ni emociones ni, mucho menos, "valores" o preferencias del observador. Éste debe desprenderse de toda subjetividad cuando entra al santuario de la ciencia, el laboratorio, como quien se despoja de su abrigo al entrar a su morada. William James, fundador de la psicología experimental en América, se declarará toda su vida un firme partidario de los "hechos irreductibles y obstinados" (7).

El proceso histórico de la "invención" de las ciencias fisiológicas revela un proceso interesante. De ser descripción desapasionada y veraz de lo que ocurre "en realidad" tales disciplinas pasan insensiblemente a convertirse en forjadoras de cánones y normas. La legalidad del comportamiento del ser humano es la que dicta el gabinete del anatomista y del fisiólogo. Las largas descripciones del clásico de Testut y Latarjet son hoy instructivas por lo que revelan de este espíritu normativo. La fisiología, que es ya una disciplina independiente y más que una simple "anatomía animada", busca las reglas de los acaeceres en el tiempo, los ritmos de la función orgánica, los grafica sutiles instrumentos (el kimógrafo de Ludwig es sólo el primero de una serie de polígrafos que registran el cambio y se sirven del tiempo como variable, inaugurando la temporalidad como variable orgánica).

La norma anatómica y la ley fisiológica no son conocimiento exclusivo de unos pocos sabios. Mediante ellas se construye el universo de acciones de la medicina porque ésta no es sino la ciencia en su operatividad técnica. No es de extrañar que los aparatos del clínico se refinen a tenor de lo que los fisiólogos y otros científicos descubren e inventan. La radiología torna transparente el cuerpo, así como el psicoanálisis vuelve transparente el alma y la fisiología torna graficable el acontecer orgánico en esos "años milagrosos" del XIX finisecular. Una avalancha de medios de observación mediatizan las percepciones sensoriales del médico y les otorgan la respetabilidad de la ciencia (8).

Más trascendental es lo que ocurre en la medicina como práctica social (9). Al ser fisiología aplicada alcanza la respetabilidad científica que asegura lo ineluctable de sus directrices. Define lo "normal" de modo inequívoco. Pero en la vida diaria, la medicina es solicitada ante decisiones de muy diverso orden. Por ejemplo, el médico debe dictaminar cuándo un trabajador ya no puede rendir más, cuándo es "anormal" y se encuentra presumiblemente 
enfermo. La medicina se ve obligada a equiparar anormalidad fisiológica con enfermedad. La "medicina social" está plagada de incertidumbres que los sabios del laboratorio no interpretan ni comprenden. Hay enfermos graves que siguen trabajando y sanos que se quejan y son improductivos. Las personas se adaptan a las condiciones y ambientes más "inhumanos" y por ende anormales sin queja ni menoscabo. Otros, en cambio, rodeados de privilegios, caen en la inutilidad.

Es en torno a los problemas derivados del "trabajo" y su función social que la medicina "fisiológica" o "científica" encuentra sus primeros escollos. La relación lineal entre "valores de laboratorio" y "vida sana", exigida por la metáfora de la máquina humana, no parece cumplirse cabalmente. El médico se ve exigido por el Estado y el capital a dar respuestas que no están en las ciencias y se sigue sirviendo, sin advertirlo ni decirlo, de la vieja prudencia ancestral del oficio. Las especialidades médicas, especialmente las limítrofes como la psiquiatría, se practican en un clima de "doble conciencia" (10). Institucionalizan lo que luego en el psicoanálisis se llamará la "competencia técnica" versus la "competencia privada". Se dice que se hace lo que en verdad no se hace y se hace lo que no se dice. Basta examinar a este respecto las evaluaciones ergonométricas y los sistemas de seguridad social para percatarse de que el cuerpo normal, fisiológico, no aparece en la forma nítida y elocuente que esperan los científicos. Peor aún. Solapadamente se introduce en la medicina científica un factor reconocido muy tardíamente: el efecto de la cultura. Toda la patología de un Metchnikoff se basaba en la putrefacción intestinal, la medicina alemana vivía de una exagerada atención al sistema cardiovascular, la francesa en cambio radicaba en los trastornos digestivos. No hay lugar aquí para discutir las vertientes históricas de estas preferencias, tan notorias cuanto más negadas, y especialmente evidentes, de nuevo, en la marginalidad de las nuevas especialidades como la psiquiatría y la epidemiología. En ellas, explícitamente, se reconoce la influencia de factores "paramaquinísticos", aquellos que están junto a la máquina corpórea pero no son parte de ella ni a ella reducibles.

\section{Deporte y nocividades ambientales}

La cartografía de la "normalidad normativa" de la fisiología empieza a perder sus contornos en otras dos situaciones que por vía de ejemplo comentaremos.

La primera se refiere el deporte. Ya en el ámbito del trabajo se observa una pérdida de los límites entre lo normal y lo anormal. La "sobreexigencia" se convierte en la condición "natural" mas no por ello "normal". El que trabaja más allá de sus fuerzas o las exige a menudo es héroe cívico. El estrés es símbolo de posición de responsabilidad y entrega societaria. Pero la idea del trabajo como factor patogénico concita universal aceptación. No ocurre lo mismo con el deporte. Este se convierte en el "locus" social por excelencia de lo anómalo. El deportista profesional y el de selección, aquél que convoca el barón Pierre du Coubertin para reinaugurar los juegos olímpicos a fines del siglo XIX, es una persona que funciona en condiciones que los seres humanos corrientes no tolerarían. Lo anormal es su medio natural. La sobreexigencia del atleta es algo que todo el mundo acepta porque parece llevar los límites de la máquina humana más allá de toda concebible perfección. Marcas mejores en velocidad, resistencias inusuales a exigencias de la naturaleza, tales son solamente algunos "desafíos" de los que pueden sentirse orgullosas naciones enteras. La "estabilidad" del cuerpo "sano", sus límites, son un campo fértil para ensayar la transgresión sistemática que imponen las disciplinas deportivas, mezcla de regularidades fisiológicas con anomalías notorias, determinación y capacidades psicológicas fuera de lo corriente. Si en el campo del trabajo, la adaptación a las exigencias anómalas tiene signo negativo, en el deportivo es fuente de recompensas importantes.

Lo importante es destacar que una flagrante transgresión a la normatividad de las ciencias fisiológicas es celebrada y deplorada al mismo tiempo. Porque así como hay deportes enaltecedores y trabajos muy dignos, hay deportes degradantes y trabajos inhumanos. Unos y otros sobreexigen a la máquina humana y obligan a ésta a utilizar su "sabiduría" para adaptarse. Se recordará que el fisiólogo Walter 
Cannon bautizó uno de sus libros más conocidos precisamente como The wisdom of the body, título que resuena ya dogmático. Desde un punto de vista cultural, interesa destacar que los límites entre normal y anormal no pasan por la simple lectura de índices fisiológicos, pues de ser así el deportista de excepción sería obviamente anormal y sin embargo debiera estar sano. La metáfora del cuerpo maquinal se "fluidifica" y se hace inestable, pues nadie puede anticipar hasta dónde llegará la plasticidad del cuerpo y sus potencialidades hacen esperar siempre más perfeccionadas habilidades. La fantasía se abre aquí a imaginar que las ciencias derrotarán a la enfermedad y la muerte y a suponer que la medicina ya no solamente cuidará, sanará y curará (sus tradicionales misiones) sino también mejorará y perfeccionará. Lo artificial se convierte en natural, lo inhumano es humano.

En esta perspectiva quisiéramos situar el debate sobre la transgresión que representan las manipulaciones del ambiente, en la medida que ellas modifican la vida de las personas. Una "ética del ambiente" (ecoética) no tiene sentido si no es en relación a los individuos humanos, las personas y las sociedades que han de habitarlo, utilizarlo, gozarlo o rechazarlo (11). La normatividad fisiológica a su vez presupone una constancia del ambiente y encuentra en sus parámetros ideales el fundamento de sus idealizadas construcciones. La máquina fisiológica trabaja en el contexto de otra "máquina" de circunstancias apropiadas, un ambiente saludable. De otro modo, se desajusta y no rinde. La fantasía normativa de lo que "debe ser" se traslada insensiblemente de las variables físicas y químicas a los principios supuestamente rectores de los ambientes deseables por naturales y promotores de vida y bienestar. Así, organismos modificados genéticamente, dosis elevadas de radiaciones ultravioleta, pérdida de la protección de la capa de ozono, calentamiento global, alteración de los ciclos naturales movilizan las conciencias y alertan a las multitudes. Lo "natural" es añorado como paraíso perdido y las controladas transgresiones de la ciencia despiertan los ancestrales temores de la destrucción total o las implacables desdichas de lo que se hace contra natura.

La primera reacción frente a los desa- rrollos técnicos es temor. Salvo los expertos, que en ellos ven la razón de ser de su eficacia inventiva, la gente en general desconfía. Desconfía de los trenes, de la electricidad, de los medicamentos. Primero, porque cada avance va acompañado de una dosis de libertad y sus efectos son impredecibles. Agoreros de todo tipo vaticinaban la inminente destrucción de la campiña y de la vida al paso de los ferrocarriles, nostálgicos deseaban que no se difundiera el peligroso invento de la luz eléctrica. En el terreno biológico, la creación de formas inéditas de vida, o aun el descubrimiento de condiciones diferentes de las habituales, producen el espanto de la desmesura. Frente a ello, la pujanza teórica de la biología molecular y de la genómica y sus esperables frutos técnicos engendran optimismo en aquellos que verán recompensados sus esfuerzos o satisfechas sus esperanzas.

La nocividad del ambiente se convierte en un tema para el imaginario colectivo precisamente allí donde parecen radicar sus más poderosos efectos, esto es, en los cambios que fraguarán y en la historia que modificarán. La calidad de la vida se reconoce vinculada a las condiciones ambientales, de modo que cualquier cambio en éstas la amenaza.

La idea del ambiente patogénico se transforma en un "problema técnico sin solución técnica". La depredación de los recursos naturales, la contaminación atmosférica, la manipulación de los organismos vivientes fallan justamente allí donde son más exitosos. Generan condiciones de peligrosidad o bien desigualdades en el acceso a sus potenciales bienes. La respuesta suele darse en diversidad de formas. Para el ciudadano corriente, la expectativa de que los expertos resolverán los dilemas. Para algunos creyentes, en la aplicación irrestricta de sus convicciones sobre lo que es "natural" u ordenado por la divinidad. Para los fetichistas del progreso, en una adecuada ponderación de riesgos y beneficios atenida a las consecuencias del desarrollo técnico.

Se observará que en todos estos escenarios los problemas no son solucionables mediante la aplicación de la racionalidad instrumental, ni siquiera empleando adecuadas estrategias de convencimiento. Las nocividades ambientales replican las nocividades corpora- 
les debidas a la ruptura de los límites históricos de la construcción científica del cuerpo. Ya son preguntas morales, que no técnicas, las que ocupan a los expertos y la gente común. Cómo ellas se formulan, en qué planos discursivos y de comunicación han de situarse, cuál será la potencia vinculante de las respuestas, cómo se armonizarán las racionalidades y los discursos, todos estos -y otros - son temas para una "bioética proactiva". Tal es la reflexión y la deliberación que no esperarán la transgresión para intervenir sino anticiparán los riesgos y permitirán a los actores sociales tener la responsabilidad que el futuro demanda.

Iniciamos este artículo con la idea de que la "fluidificación" de la imagen del ser humano fue logro de las ciencias sociales que así modularon el pensamiento de la fisiología mecanicista. Quisiéramos sugerir que la aplicación consecuente de las "nuevas humanidades" (ciencias sociales y bioética) a los problemas ambientales podrían lograr el necesario equilibrio discursivo para que el desafío en el futuro no consista en tener más ciencia y mejor medicina sino mejor ciencia y medicina más humana. El examen histórico de estas cuestiones es todavía una tarea inconclusa.

\section{Referencias}

1. Lolas F. La perspectiva psicosomática en medicina. $2^{a}$ ed. Santiago de Chile: Universitaria; 1995.

2. Sarasin P, Tanner J (eds ). Physiologie und industrielle Gesellschaft. Frankfurt/Main: Suhrkamp Verlag; 1998.

3. Barsch A, Heijl PM (eds ). Menschenbilder. Zur Pluralisierung der Vorstellung von der menschlichen Natur. Frankfurt/Main: Suhrkamp Verlag; 2000.

4. Engelhardt T. Los fundamentos de la Bioética. Barcelona: Paidós; 1995.

5. Lolas F. Bioética y antropología médica. Santiago de Chile: Mediterráneo; 2000. 
Normatividad fisiológica y nocividad ambiental... F. Lolas S.

6. Lolas F, Vargas L (eds ). Fundamento fisiológico de la medicina. Santiago de Chile: Ediciones Pontificia Universidad Católica de Chile; 1986.

7. Lolas F. Introducción histórica a la psicología fisiológica. Santiago de Chile: Universitaria; 1979.

8. Lolas F. Proposiciones para una teoría de la medicina. Santiago de Chile: Universitaria; 1992.

9. Lolas F. Las transformaciones de la medicina: modelo farmacéutico y ciencias sociales. En: Lolas F, Florenzano R, Gyarmati G, Trejo C (eds). Ciencias sociales y medicina: perspectivas latinoamericanas. Santiago de Chile: Universitaria; 1992. pp. 21-9.

10. Lolas F. La psicofisiología como una ciencia básica de la psiquiatría. Acta Psiquiátrica y Psicológica de América Latina (Buenos Aires) 1984; 30:184 - 92.

11. Lolas F, Marinovic M. La dimensión humana del ambiente. Santiago de Chile: Universidad de Chile; 1995. 